\title{
Psychometric properties and parental reported utility of the 19-item 'About My Child' (AMC-19) measure
}

\author{
Uzma Williams* D, Peter Rosenbaum, Jan Willem Gorter, Dayle McCauley and Roman Gulko
}

\begin{abstract}
Background: 'About My Child' 19-item version (AMC-19) is a parent-report measure developed to assess the complexity of a child's life due to biological, psychological, social and environmental issues, that can be completed in approximately $5 \mathrm{~min}$. AMC measures two dimensions of complexity: parental concerns and impact on the child. This paper examines the psychometric properties and parent-reported utility of the AMC-19 for children with disabilities or special health care needs.

Method: Data were gathered from two Canadian studies at CanChild: the 'AMC-19 Pilot' study and the 'Service Utilization and Outcomes (SUO)' study. The AMC-19 Pilot study data allowed us to explore internal consistency and test-retest reliability, as well as parental responses to two open-ended questions on the utility of the AMC-19. The SUO study provided data for analyses of internal consistency and scale property validation with type of diagnosis and service needs.

Results: The test-retest ICC was $r=0.83$ for concerns and $r=0.87$ for impact. Cronbach's alpha across both studies ranged from 0.80 to 0.90 . Parents' comments on the AMC-19's utility indicated support for the AMC-19, in particular to identify therapy needs and goals.

Conclusions: The AMC-19 demonstrates strong psychometric properties supporting it as a valuable measure for describing the level of complexity among children with disabilities. We recommend using the AMC-19 in health services research and clinical settings to build dialogue between family and therapists due to its utility reported by parents.
\end{abstract}

Keywords: About My Child, Childhood, Complexity, Development, Disability, International Classification of Functioning, Disability and Health, Reliability

\section{Background}

Understanding and assessing childhood impairment and disability remain significant public health concerns. More than 93 million (or 5.1\%) children and adolescents below age 15 live with a childhood disability around the world [1]. Children with disabilities are often diagnosed with multiple 'primary' health conditions, while associated impairments ('co-morbidities') vary greatly in both scope and severity, resulting in a need for a wide variety of additional services and supports [2]. Children with

\footnotetext{
* Correspondence: williau@mcmaster.ca

School of Rehabilitation Sciences, CanChild, McMaster University, Institute for Applied Health Sciences, 1200 Main Street West, Hamilton, ON L8N 3Z5,
} Canada

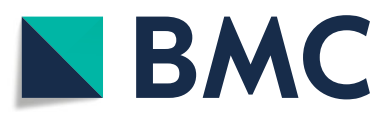

(c) The Author(s). 2018 Open Access This article is distributed under the terms of the Creative Commons Attribution 4.0 International License (http://creativecommons.org/licenses/by/4.0/), which permits unrestricted use, distribution, and reproduction in any medium, provided you give appropriate credit to the original author(s) and the source, provide a link to the Creative Commons license, and indicate if changes were made. The Creative Commons Public Domain Dedication waiver (http://creativecommons.org/publicdomain/zero/1.0/) applies to the data made available in this article, unless otherwise stated. of their health care needs, and this reality often impacts their quality of life and that of their families [3]. In order to provide families using rehabilitation services with optimal care as well as improved living standards and life quality, it is important to describe, measure, and assess accurately the 'complexity' of children with impairments or special health care needs.

Defining complexity has proved to be a troublesome task by virtue of the clinician's dependence on contextual and subjective information. In addition, due to the lack of a clear definition, "complexity" has been erroneously conflated with other constructs such as co-morbidity and severity $[4,5]$. Nonetheless, several attempts have been 
made to define complexity. A comprehensive description of complexity has been provided as the cumulative number of biological, psychological, social and environmental issues in a child's life that directly (and usually negatively) impact the child's health and care needs [5]. This notion proposes that the simple cumulative count of child health-related issues and their impact is more salient than the severity of each individual issue. Complexity is differentiated from a variety of related concepts, including disease severity, illness severity, comorbidity, functional ability, health utility, quality of life, and others [6].

It is argued that thinking about complexity in this way is a more useful indicator of functioning in daily life activities than severity of the condition(s), because the latter does not consider or aggregate the multiple areas of concern or the magnitude and cumulative impact of these concerns. One can have an objectively observed 'functional limitation' - some limited level of capacity to do something - and have good accommodations that allow people to 'do' things even if they 'do' them differently from what is considered typical. For example, a child may have a walking limitation. With modifications in their home and school environment, this child may not be limited in independent mobility or participation in daily life activities, so the impact of the body-level impairment is minor. On the other hand, another child with the same level of functional limitation may report a higher level of complexity and thus find difficulty engaging in daily life activities if environmental modifications do not accommodate their needs (or indeed if additional functional challenges are present). In this situation, the parents of the second child will almost certainly report a higher level of concern and complexity.

Although several instruments and methods have been designed to measure complexity in adult health, one tool that measures complexity in children with disabilities by using a parent proxy response is the About My Child (AMC) measure [6]. The AMC measures child health complexity and has been proposed as a tool to understand the cumulative functional needs of children and the priorities of their families. The AMC measure was created in the context of the International Classification of Functioning, Disability and Health (ICF) framework (see Table 1), which is a classification framework used for measuring health and disability [7].

While the AMC was developed empirically, it has been used by students and researchers at CanChild despite the absence of a formal measurement development process. Two versions of the AMC exist: an earlier 26-item version and a later 19-item version presented here, both available from CanChild [6].

While Ritzema and Lach [8] reported on the reliability and validity of the 26-item AMC measure, showing good internal consistency (Cronbach's alpha $=0.75$ to 0.85 ), they also indicated the need for completing test-retest for the measure, in addition to exploring clinical utility. Factor analysis was conducted on the original 26-item AMC measure (not shown) to explore the principal component loadings. Items were optimized and redundant items were removed, producing the current 19-item AMC version (hereafter referred to as the AMC-19).

The purpose of the current report is to assess the psychometric properties and 'performance' of the AMC-19. Assessing the capability of the AMC-19 may validate its use in health services research and advance the use of the AMC-19 in clinical applications, such as for collaboration between clinicians and parents for functional goal setting in line with family-centred care. This paper reports the test-retest reliability, scale properties, and parent reported utility of the AMC-19, using data from the Pilot study and the Service Utilization and Outcomes ('SUO') study [9].

\section{Methods \\ Measures \\ AMC}

The AMC-19 is designed to allow family members and caregivers to highlight the issues that are important to each individual family regarding the condition and care of their child. It does so using a checklist of the most common parental concerns (for example, ability to move around, feed/eat, toilet, understand, communicate, learn, participate in activities, etc.). Each item has a similar structure, with two parts to each question reporting two components: concern and perceived impact, both indicating complexity. Concern refers to the parents' perception about issues affecting their child's functioning, and the extent to which that concern (if present) is thought to impact the child's life and function. Parents rate the concern questions as either "yes" or "no" for each of the items. Each item states: "I am concerned about my child's... [e.g., "Ability to move around at home, school and community"]. If the parent answers "yes", they are asked to respond to: "If yes, does this impact on their ability to participate in everyday activities?" ranging on a four-point response option from "not at all" to "a lot". The first approach to score the AMC-19 counts the number of concerns parents have about their child. Areas of concern are reported by summing the number of issues identified by parents. Items scored "yes" receive 1 point whereas a response of "no" is scored as 0 , with 'concern' scores ranging from 0 to 19 . The second component, impact, reports on the parent's perceptions of the complications in the child's life imposed by the issues they have identified. Each item that is indicated as a concern by checking "yes" is rated on a 4-point Likert-type scale to assess the impact on the child's functioning 1 ("not at all"), 2 ("a little"), 3 ("somewhat"), and 
Table 1 ICF Coding for the AMC Measure ${ }^{a}$

\begin{tabular}{|c|c|c|}
\hline Question I am concerned about my child's: & ICF Chapter & ICF Codes \\
\hline 1. Ability to move around at home, school and community & AP-4 - Mobility & d 460 \\
\hline 2. Ability to use their hands and arms to do the things they want to do & AP-4 - Mobility & $d 445, d 440$ \\
\hline 3. Ability to perform functions such as feeding/eating & AP-5 - Self-Care & d 550, d 560 \\
\hline 4. Ability to carry out toileting & AP-5 - Self-Care & d 530 \\
\hline 5. Ability to dress or undress self & AP-5 - Self-Care & d 540 \\
\hline 6. Ability to sleep each night & BF-1 - Mental Functions & b 134 \\
\hline 7. Seeing & BF-2 - Sensory Functions & b 210 \\
\hline 8. Hearing & BF-2 - Sensory Functions & b 230 \\
\hline 9. Ability to understand other people & $\begin{array}{l}\text { BF-1 - Mental Functions, } \\
\text { AP-3 - Communication }\end{array}$ & b 1670, d 310, d315 \\
\hline 10. Ability to tell people what they want & $\begin{array}{l}\text { BF-1 - Mental functions, } \\
\text { AP-3 - Communication }\end{array}$ & b 1671, d 330, d 315 \\
\hline 11. Behavior & AP-2 - General tasks and demands & $d 250$ \\
\hline 12. Mood & BF-1 - Mental Functions & b 152 \\
\hline 13. Pain & BF2 - Sensory Functions & b 280 \\
\hline 14. Ability to learn new things & $\begin{array}{l}\text { BF-1 - Mental Functions, } \\
\text { AP-1 - Learning and applying knowledge }\end{array}$ & b 163 , d 130-d159 \\
\hline 15. Ability to remember things they know & $\begin{array}{l}\text { BF-1 - Mental Functions, } \\
\text { AP - } 1 \text { Learning and applying knowledge }\end{array}$ & b 144 , d 179 \\
\hline 16. Ability to get along with other children & AP-7 - Interpersonal relationships & d 7504 \\
\hline 17. Ability to get along with adults & AP-7 - Interpersonal relationships & d 7203, \\
\hline 18. Participation in activities at home & - & d 880 \\
\hline 19. Participate in activities at school or in the community & $\begin{array}{l}\text { AP-8 - Major life areas, } \\
\text { AP-9 - Community, social and civic life }\end{array}$ & d 820, d 910 \\
\hline
\end{tabular}

${ }^{a}$ The ICF encompasses four major health domains: body functions (b), body structures (s), activities and participation (d), and environmental factors (e), and is organized using alphanumeric codes. The letter within the alphanumeric code corresponds to a health domain and the numbers act as qualifiers, indicating severity. The AMC inventory was created so that each of the 19 items on the questionnaire corresponds to an ICF alphanumeric code. Table 1 summarizes the main focus of each AMC item and its relationship with its corresponding ICF code

4 ("a lot"). Thus, if the respondent replies "yes" to the first part of an item, then the value of "yes" (1) is multiplied by the value of the response to the second part. The scores of all 19 items are then summed for a total 'complexity' score that can range from 0 to 76 . The AMC-19 can be completed in approximately 5 min.

\section{Supports and Services (SAS) questionnaire}

The SAS questionnaire provides an understanding of the perceived service needs required by the child and their family [10]. The SAS is a 28-item list inventory split into two sections, with 14 child items and 14 family items. Psychometric evaluations of the SAS have not been conducted due to the dynamic nature of the measure [Jean Summers, personal communication, February 17, 2016]; however, the clinical utility and its use in a treatment outcome measurement system for children using a CTC are supported [11]. Like the AMC-19, the SAS is structured with a stem that asks "Does your child currently need..." e.g., "special equipment". The parent can respond "Yes" or "No". Each question then asks "If yes, how much service does he or she get?" with three response options of "none", "some but not enough", or "enough". For the purpose of this study, the SAS was scored similarly to the AMC. The researchers of this study provided a score of 1 to "yes" and 0 to "no" and then multiplied this score by 3 ("none"), 2 ("some but not enough"), or 1 ("enough") services received. The possible range is 0 to 78 , with a higher score indicative of the family needing more services.

\section{Data sources for establishing psychometric properties and clinical utility}

The sources of the two datasets used to assess the psychometrics of the AMC-19 are summarized below. Both studies met sample size requirements for conducting reliability analysis [12]. Ethics approval was obtained from McMaster University and Hamilton Integrated Research Ethics Board for the AMC-19 Pilot study and SUO study, respectively.

1) AMC-19 Pilot study: The AMC-19 Pilot study was part of a larger body of work conducted by CanChild between 2004 and 2008. During this period, 
CanChild was developing a provincial measurement system to help government assess services to determine meaningful outcomes for children and youth with special needs and their families [11]. In consultation with various stakeholders, the ICF framework [7] for this system was chosen along with several instruments that were identified to be the best specific measures to evaluate the constructs of interest [11]. The best measure of body function and structure was determined to be the AMC-19, however, at the time no information was available on its psychometric properties. To gather information about the reliability of this measure, a group of researchers worked in partnership with selected publicly-funded regional Southern Ontario Children's Treatment Centres (CTCs) to assess test-retest reliability of the AMC-19 as part of a larger study to assess the test-retest reliability of the Craig Hospital Inventory of Environmental Factors (CHIEF) for children 2-12 years of age [13]. This pilot study used cold one-time mail-out to distribute 450 surveys to families in three CTCs in Ontario (packages were sent directly from the respective CTCs) and received data from 61 families. The initial correspondence and survey were mailed out in March 2009 and a retest survey was mailed 2 weeks after the initial questionnaires were received at CanChild. Of the 61 initial returned packages, 45 (73.8\%) retest packages were received at CanChild.

2) SUO study: The SUO study recruitment and methods are described in detail in Williams' $\mathrm{PhD}$ dissertation [9]. Using a cross-sectional design, the SUO study explored personal, family, and environmental factors of children using a CTC in Southern Ontario. The online survey completed by parents included demographic questions, AMC-19 measure, SAS questionnaire, as well as measures of children's participation and family-centred practices. Seven hundred families were invited to the study and 202 fully completed the AMC-19 used in this analysis.

\section{Study participants}

Participant demographics are summarized in Table 2. The participant groups in both studies consisted of parents of more males than females $(65.6 \%$ in the AMC- 19 Pilot study and $61.9 \%$ in the SUO study) with a mean of 6 years $(\mathrm{SD}=3.0)$ in the AMC-19 Pilot study and 4.5 years $(\mathrm{SD}=3.0)$ in the SUO study. The primary diagnoses of children varied in the AMC-19 Pilot and SUO studies, and included Autism Spectrum Disorder (ASD)-related disorders, speech difficulties, cerebral palsy (CP), Developmental Delay (DD) such as learning or motor delays, syndromes such as Down Syndrome, and children diagnosed with two or more conditions. The primary diagnosis in the AMC-19 Pilot study was DD $(n=17,27.9 \%)$; in the SUO study, the communication disorder/speech delay diagnoses involved 63 participants (25.0\%), and DD diagnoses involved 53 participants (21\%). In the AMC-19 Pilot study, parent reported complexity scores ranged from 7 to 69 on initial completion and 2 to 65 on retest completion. Complexity scores ranged from 1 to 56 in the SUO study.

\section{Data analyses \\ Reliability}

The reliability assessment was conducted with the proposition that the underlying structure of the AMC-19 is unidimensional. 'Concern' as a binary variable and impact as an ordinal variable can show discriminant differences for test re-test and internal consistency [14, 15]. Internal consistency was tested using Cronbach's alpha in both the AMC-19 Pilot and SUO study. Each study provides a Cronbach alpha score on the concern and impact components. Test-retest reliability was carried out on the AMC-19 Pilot data. The Intraclass correlation (ICC) coefficient was set to 0.80 , with the authors willing to accept values of 0.6 or higher.

\section{Assessment of scale properties}

To assess scale properties, the relationships between AMC-19 impact scores, primary diagnosis, and parent-reported service needs were explored from the SUO dataset using Spearman's Rho correlations and Kruskal-Wallis test. We hypothesized a priori that diagnoses that are linked to multiple areas of concern will present higher complexity scores. To assess scale properties, we also predicted a positive correlation between AMC-19 impact scores and increased perceived service needs and service utilization.

\section{Parental responses}

On the initial mail-out parents were asked two open-ended questions on the AMC-19 Pilot survey, and the responses were compiled in the AMC-19 Pilot study database. The first question was: "Are there other things that worry you?", followed by the second question: "Please feel free to comment on the content of the survey".

An open inductive thematic analytic approach was used to explore the two questions based on general grounded theory [16]. Comments were repeatedly read until the content was understood. Next, codes (sometimes multiple codes) were marked in each comment, with the codes representing the core idea(s) of the comment. These codes were grouped into broader concepts and categories with a frequency count to manage how often parents reported them. The comparisons of category codes were made after the analysis to confirm the findings. Discrepancies were discussed and resolved by 
Table 2 Participant characteristics

\begin{tabular}{|c|c|c|c|c|}
\hline \multirow{2}{*}{$\begin{array}{l}\text { Demographic } \\
\text { Child's age }\end{array}$} & \multicolumn{2}{|c|}{$\begin{array}{l}\text { AMC Pilot Data } \\
\text { N (\%) }\end{array}$} & \multicolumn{2}{|c|}{$\begin{array}{l}\text { SUO Data } \\
\text { N (\%) }\end{array}$} \\
\hline & & & & \\
\hline $0-2$ years 11 months & 3 & $(4.9)$ & 43 & $(17.1)$ \\
\hline $3-5$ years 11 months & 29 & $(47.5)$ & 170 & $(67.4)$ \\
\hline 6-11 years 11 months & 27 & $(44.3)$ & 26 & $(10.3)$ \\
\hline 12 years and older & 2 & (3.3) & 13 & $(5.2)$ \\
\hline \multicolumn{5}{|l|}{ Child's sex } \\
\hline Male & 40 & $(65.6)$ & 156 & $(61.9)$ \\
\hline Female & 21 & $(34.4)$ & 96 & $(38.1)$ \\
\hline \multicolumn{5}{|l|}{ Child's diagnosis } \\
\hline Acquired brain injury & 1 & $(1.6)$ & 8 & $(3.2)$ \\
\hline ASD-related disorders/PDD & 7 & $(11.5)$ & 26 & $(10.3)$ \\
\hline Cerebral palsy & 7 & $(11.5)$ & 20 & $(8.0)$ \\
\hline Communication disorder/speech delay & 3 & $(4.9)$ & 63 & $(25.0)$ \\
\hline DCD & 2 & (3.3) & 1 & $(0.4)$ \\
\hline DD & 17 & $(27.9)$ & 53 & $(21.0)$ \\
\hline Neuromuscular disease (including muscular dystrophy) & 2 & (3.3) & 5 & $(2.0)$ \\
\hline Spina bifida/hydrocephalus & 2 & $(3.3)$ & 3 & $(1.2)$ \\
\hline Syndrome & 9 & $(14.7)$ & 16 & $(6.3)$ \\
\hline Two or more conditions & - & - & 16 & $(6.3)$ \\
\hline Other & 11 & $(18.0)$ & 24 & $(9.5)$ \\
\hline Missing & - & - & 17 & $(6.8)$ \\
\hline \multicolumn{5}{|l|}{ Living Arrangement } \\
\hline Two-parent family & 55 & $(90.2)$ & 223 & $(88.5)$ \\
\hline Single-parent family & 6 & $(9.8)$ & 24 & $(9.5)$ \\
\hline Other & - & - & 3 & $(1.2)$ \\
\hline Missing & - & - & 2 & $(0.8)$ \\
\hline \multicolumn{5}{|l|}{ Parent's age (years) } \\
\hline $20-34$ & 18 & $(29.5)$ & 114 & $(45.2)$ \\
\hline $35-49$ & 41 & $(67.2)$ & 130 & $(51.6)$ \\
\hline $50-64$ & 2 & (3.3) & 5 & $(2.0)$ \\
\hline Missing & - & - & 3 & $(1.2)$ \\
\hline \multicolumn{5}{|l|}{ Parent's income (\%) } \\
\hline Less than $15 \mathrm{~K}$ ? & 4 & $(6.6)$ & 14 & (5.6) \\
\hline $15,000-29,999$ & 7 & $(11.5)$ & 21 & $(8.3)$ \\
\hline $30,000-44,999$ & 8 & $(13.1)$ & 21 & $(8.3)$ \\
\hline $45,000-59,999$ & 7 & $(11.5)$ & 30 & (11.9) \\
\hline $60,000-74,999$ & 11 & $(18.0)$ & 30 & $(11.9)$ \\
\hline $75,000-89,999$ & 5 & $(8.2)$ & 25 & $(9.9)$ \\
\hline More than 90,000 & 18 & $(29.5)$ & 105 & $(41.7)$ \\
\hline Missing & 1 & (1.6) & 6 & $(2.4)$ \\
\hline
\end{tabular}


Table 2 Participant characteristics (Continued)

\begin{tabular}{|c|c|c|c|c|}
\hline \multirow{2}{*}{$\begin{array}{l}\text { Demographic } \\
\text { Highest level of education completed by respondent }\end{array}$} & \multicolumn{2}{|c|}{$\begin{array}{l}\text { AMC Pilot Data } \\
\text { N (\%) }\end{array}$} & \multicolumn{2}{|c|}{$\begin{array}{l}\text { SUO Data } \\
\text { N (\%) }\end{array}$} \\
\hline & & & & \\
\hline Some high school (grades 9-11) & 2 & (3.3) & 11 & $(4.4)$ \\
\hline Completed high school & 8 & $(13.1)$ & 28 & $(11.1)$ \\
\hline Some college or technical training & 6 & $(9.8)$ & 17 & $(6.7)$ \\
\hline Completed college or technical training & 20 & $(32.8)$ & 64 & $(25.4)$ \\
\hline Some university (at least 1 year) & 10 & $(16.4)$ & 14 & $(5.6)$ \\
\hline Completed university degree & 15 & (24.6) & 113 & $(44.8)$ \\
\hline Missing & - & - & 5 & (2) \\
\hline
\end{tabular}

ASD Autism Spectrum Disorder, DCD Developmental Coordination Disorder, PDD Pervasive Developmental Disorder, SUO Service Utilization and Outcomes

adopting the category titles that were most reflective of the codes within the category until consensus was achieved on all categories. The thematic analysis process and final categorical themes were presented and discussed to ensure a fault did not occur during coding the categories, and the categories were representative of the original parent comments. No theory was generated because the purpose of establishing the categorical themes was to obtain descriptive insights into parental perceptions regarding the utility of the $\mathrm{AMC}-19$ measure from each of the two questions.

\section{Results}

AMC-19 pilot study

\section{Internal consistency}

The internal consistency of the AMC-19 for the concern component, evaluated using Cronbach's alpha, was satisfactory in both the AMC-19 Pilot Time $1(n=58)$ and Time $2(n=39)$ with values of $\alpha=0.84$ and $\alpha=0.81$, respectively. The internal consistency for the impact component was $\alpha=0.80$ for Time $1(n=55)$ and $\alpha=0.81(n=42)$ for Time 2.

\section{Test-retest}

Of the 45 packages returned for the AMC-19 Pilot study, a total of 39 pairs of complete data were available. Six participants were omitted due to missing data so no complexity score was computed. No imputing or replacement of missing values was conducted on the 39 pairs of complete data. Test-retest correlation coefficients for the AMC-19 included an ICC of $0.83(p<0.001)$ for the 'concerns' and $0.87(p<0.001)$ for the 'impact' scores.

\section{SUO study Internal consistency}

The internal consistency using Cronbach's alpha was satisfactory in the SUO study for concern $(\alpha=0.87, n=186)$ and impact $(\alpha=0.90, n=183)$. The individual items with the lowest correlations to the full measure total correlation included hearing $(r=0.14)$, mood $(r=0.27)$, and pain $(r=0.20)$. Cronbach's alpha would remain stable between values of $r=0.85$ to 0.87 if any of the concern items were to be deleted.

Scale properties: Primary diagnoses, service need, and AMC19 scores

Table 3 shows AMC-19 impact scores arranged by primary diagnosis using the SUO data. Children classified with ASD-related diagnoses showed the highest median score $(n=25$, median $=30$, interquartile range (IQR) $25=$ 17 , IQR $75=41.5$ ); whereas children using the centre for speech services presented the lowest complexity scores $(n$ $=46$, median $=4$, IQR $25=2$, IQR $75=10$ ). A statistically significant difference was found in AMC-19 impact scores among the majority of primary diagnosis groups as determined by a Kruskal-Wallis test, $\mathrm{X}^{2}(9)=66.2, p<0.001$.

Table 3 Primary Diagnosis and AMC Score

\begin{tabular}{lllllll}
\hline & ASD-related disorders/PDD & CP & DD & Speech & Syndrome & 2 or more Conditions \\
\hline Sample Size & 25 & 20 & 48 & 46 & 16 & 15 \\
Missing & 1 & 0 & 5 & 17 & 0 & 1 \\
25th Quartile & 17.0 & 12.5 & 8.0 & 2.0 & 9.8 & 8.0 \\
50th Quartile & 30.0 & 22.5 & 15.5 & 4.0 & 24.5 & 14.0 \\
75th Quartile & 41.5 & 37.8 & 25.8 & 10.0 & 31.5 & 29.0 \\
K-Wallis Ranking* & 145.6 & 131.3 & 104.6 & 50.6 & 124.8 & 101.4 \\
\hline
\end{tabular}

${ }^{*}$ All diagnostic categories significant $(p<0.05)$ except 1$)$ CP and syndrome, and 2) DD and 2 or more conditions

ASD, Autism Spectrum Disorder; CP, Cerebral Palsy; DD Developmental Disabilities; PDD, Pervasive Developmental Disorder 
Whitney post-hoc tests with Bonferroni correction showed significant differences among all the diagnostic categories at a $p$-value of $<0.05$, with the exception of 1 ) $\mathrm{CP}$ and syndrome, and 2) DD and two or more conditions. This finding indicates that in most cases, the AMC-19 detected that median impact scores vary significantly by clinical diagnosis, and the interquartile distribution supports that complexity scores vary within diagnoses.

Spearman correlations between AMC-19 concern and SAS scores ranged from $r=0.32$ to $r=0.65$, all $p<0.001$, and the correlations between complexity and SAS scores ranged from $r=0.31$ to $r=0.62$, all $p<0.001$ (Table 4). This finding supports that families with higher complexity scores on average perceive higher need for services.

\section{Parental comments on the AMC-19 measure} Question one: "Are there other things that worry you?"

Forty parents responded to the first question, with many comments having multiple codes identified (Table 5). Three major categories were created in the analysis: 1$)$ functioning, 2) participation and sociability, and 3) life-skills.

The most common reported areas of functioning identified as a concern were language skills $(n=22)$ and motor ability $(n=19)$. The second category included participation and social elements. The largest area concerned school sociability indicated by general school integration $(n=9)$ and acceptance by peers $(n=7)$. These two areas were present- or future-worry orientation. The next largest area of concern was parents wanting their children to be more involved in recreation activities or to have activities modified for children with special needs $(n=11)$.

Parents identified a concern about life-skills, an area, unlike functioning and participation and social elements, that is not currently in the AMC-19. The codes grouped into this concept focused around improving the ability of the child to integrate better into society by improvements in behavior and adaptions to life situations and transitions.

\section{Question two: "Please feel free to comment on the content of the survey"}

In the second question, the researchers grouped the responses into aspects of the AMC-19 that parents liked and those that needed improvement $(n=15$; Table 6).
Three key themes emerged. The first was the expression of concerns. Some parents were already aware of their child's issues, so the measure did not provide new information to them. On the other hand, parents commented that the AMC-19 is a beginning point to start understanding what families with children with disabilities go through on a daily basis. Some additional comments stated that the AMC-19 allowed parents to reflect on their situation and express concern. The second theme identified is the content area covered by the AMC-19. A few parents reported that the measure is vague and did not identify specific areas. In contrast, other parents commented that a positive aspect of the AMC-19 was that the most relevant areas are explored, and parents are able to give detail and suggestions to improve change in therapy. The third theme of the AMC-19 involved parents questioning how the AMC-19 will help with planning services. Parents commented that they favor anything that makes services better and makes their "lives a little less challenging", so they see the AMC-19 as beneficial. A parent commented that the AMC-19 measure is "useful in that it's more 'parent-perspective' than a checklist of yes and no can-do items".

\section{Discussion}

\section{Psychometric properties of the AMC-19 measure}

This study presents evidence that complexity as assessed by the AMC-19 is a psychometrically sound construct that can be used to initiate dialogue and set goals for children in therapy by identifying the depth of parental concerns in specific areas of daily living. The internal consistency and test-retest scores support that the AMC-19 is a reliable measure.

The high internal consistency scores indicate that the 19-items used in the AMC measure are all necessary and make a meaningful contribution to the measure. Therefore, no items were considered for removal. In a future revision of the AMC-19, items could be added to address parent feedback in regard to general school integration, dangers in environment, handling transition periods and changes in routine, and independent living as suggested by the parents. Should that be done, further psychometric work will be required.

Table 4 SAS Scores and AMC Scores

\begin{tabular}{lllll}
\hline & & SAS Child Score & SAS Family Score & SAS TOTAL Score \\
\hline AMC Concern & Correlation Coefficient & $.61^{* *}$ & $.32^{* *}$ & $.65^{* *}$ \\
AMC Impact & Sample Size & 179 & 99 & 179 \\
& Correlation Coefficient & $.62^{* *}$ & $.31^{* *}$ & $.61^{* *}$ \\
& Sample Size & 194 & 120 & 194 \\
\hline
\end{tabular}

${ }^{* *} p<0.001$ 
Table 5 Thematic analysis of parental comments of the AMC-19

\begin{tabular}{|c|c|c|}
\hline \multicolumn{3}{|c|}{ Question 1: "Are there other things that worry you?" } \\
\hline Theme & Frequency & Comments \\
\hline \multirow[t]{5}{*}{ Functioning } & 22 & $\begin{array}{l}\text { Language skills (read, write, speak) } \\
\text { including effective communication } \\
\text { if cannot speak and more one to } \\
\text { one therapy }\end{array}$ \\
\hline & 19 & $\begin{array}{l}\text { Motor ability with physical recreation } \\
\text { activities, around home, dressing, } \\
\text { walking, toilet training, fine motor } \\
\text { skills (buttons, zippers) }\end{array}$ \\
\hline & 3 & $\begin{array}{l}\text { Cognitive ability (e.g., concentration, } \\
\text { problem solving, basic knowledge) }\end{array}$ \\
\hline & 1 & Hearing \\
\hline & 1 & Memory \\
\hline \multirow[t]{3}{*}{$\begin{array}{l}\text { Participation and } \\
\text { Sociability }\end{array}$} & 11 & $\begin{array}{l}\text { Involvement in recreation activities } \\
\text { (modified for special needs children) }\end{array}$ \\
\hline & 9 & $\begin{array}{l}\text { General school integration (such as } \\
\text { completing work and enjoying } \\
\text { learning) }\end{array}$ \\
\hline & 7 & $\begin{array}{l}\text { Acceptance by peers (present or } \\
\text { future worry) }\end{array}$ \\
\hline \multirow[t]{4}{*}{ Life-Skills } & 6 & $\begin{array}{l}\text { Behavioral control and self-regulation } \\
\text { (e.g., control temper tantrums and } \\
\text { anger, stop hitting self, be less } \\
\text { controlling, self-soothe and calm self, } \\
\text { regulate emotions, patience) }\end{array}$ \\
\hline & 5 & Awareness of dangers/safety \\
\hline & 3 & $\begin{array}{l}\text { Handling transition periods and } \\
\text { changes in routine }\end{array}$ \\
\hline & 2 & $\begin{array}{l}\text { Independent living (e.g., healthier } \\
\text { food choices, money management) }\end{array}$ \\
\hline
\end{tabular}

Table 6 Parental evaluation of positive and negative feedback of the AMC-19

\begin{tabular}{l}
\hline Question 2: "Please feel free to comment on the content of the survey" \\
\hline Positive Feedback \\
most relevant areas explored and parents able to give detail and \\
suggestions to improve of change \\
some parents found it useful for reflecting on their situation \\
parents favor anything that makes services better and makes their \\
lives a little less challenging \\
beginning point to starting to understand what families with children \\
with disabilities go through on a daily basis \\
useful in that it's more 'parent-perspective' than a checklist of yes and \\
no can-do items \\
allows for expressing concern that even if child can-do or may not be \\
good at (especially in the community) so improvements can be made \\
Negative Feedback \\
parents already aware \\
parents question how this will help with planning services \\
questionnaire vague does not get specific areas
\end{tabular}

\section{Relationship between diagnosis and complexity}

Complexity scores obtained from the AMC-19 varied both within and between diagnostic categories. While the descriptive data show there is variability among AMC-19 scores by diagnosis, this is not to suggest that one condition is more complex than another. Rather, the intention is to demonstrate that the AMC-19 discriminates levels of complexity both between and within diagnoses. Descriptively, we also found variability among the complexity scores within each diagnosis. The range of complexity scores within the diagnostic categories supports the a priori hypothesis that complexity is a unique construct that differs from child to child regardless of diagnosis. These findings support the longstanding notion of the importance of a 'non-categorical' approach to childhood disability [17]. In summary, our findings are supportive of the underlying idea that complexity (concern and impact) is fundamentally different from diagnostic category and thus needs to be measured and treated as such.

\section{Applications of parental comments: Clinical utility of the AMC-19 and implications for practice}

Parents' comments represented typical concerns of any parent raising a child, with or without a disability. The majority of comments related to areas of functioning already addressed by the AMC-19 measure with the exception of life-skills, which is currently not in the AMC-19 but was identified by parents as an area of concern. Life-skills is an important area to explore because of its emphasis on daily independent living that is not socially or functionally focused. Life-skills encompass tasks and situations that may enhance the quality of living by raising awareness in children to prevent children from entering vulnerable situations as well as increasing their confidence to handle difficult situations. On the other hand, one might argue that the need for help with 'life skills' reflects the impact of the 'basic' elements of functional challenge identified by AMC-19, and while very important, should be considered a separate aspect of the lives of young people with developmental challenges.

Many of the concerns identified in Question One were out of the parents' control - for example, enjoying school or acceptance by peers. Nonetheless, the AMC-19 identifies and voices concerns of parents, so problem areas are prioritized and plans can be created to best mitigate parental concerns. Even if a child can do a task or behavior well, improvements in a task can be monitored based on the areas identified as important by parents. While the breadth of the AMC-19 survey was identified as a limitation, it is necessary in order to capture the most common concerns across multiple areas because specific items will only lengthen the survey, causing burden on parents. Given its broad scope, and used in a clinical setting, the AMC-19 can be helpful to 
open a dialogue between the therapists/physicians and parents. The administration of the AMC-19 may assist with developing rapport between the therapist and families and also systematically identify key goals of therapy from the families' perspective. AMC-19 also assists in making parents aware that any or all of the items may be important to them, and allows for the prompt and adequate identification of goals that are important to the family. Overall, the parents' comments indicate that the use of the AMC-19 in therapy is beneficial to the family-health practitioner relationship.

This study is the first step in assessing the importance that the AMC-19 can have within a clinical setting, and parental perception of the content of the survey was a simple form of face validity. The parents' comments support that the AMC-19 explores how well the child functions regardless of diagnosis and severity. Parental responses indicate that the AMC-19 measure would have utility in clinical therapy settings by exploring individual functional limitations in the home, school, and community. We suggest therapists provide the AMC-19 measure to parents at the start of therapy or when functional goals are difficult to identify.

\section{Limitations}

The main limitation of both studies is that data were collected from one CTC for the SUO study and three CTCs for the AMC-19 Pilot study, so the range of impairments may have been constrained in some way. We did not sample for a specific number of children with each diagnosis, so the results of the complexities scores are a reflection of the families/parents that responded and were willing to participate in the studies. For example, families from the SUO study reflect a sample with high income and young children. However, respondents with a higher socioeconomic status tend to respond more often to voluntary surveys [18], and children of younger age groups show higher proportions of utilization at CTCs [19-22]. To mitigate issues of representativeness, only descriptive statistics and median rankings were appropriate to analyze on the primary diagnoses and AMC-19 scores, and while we believe the study has internal validity, we caution that no generalizable conclusions about the population have been or should be drawn. Nor do we make implications to infer that specific diagnoses equate to higher or lower complexity levels. In this measurement development study, our goal is not to generalize or draw inferences about the clinical diagnostic population but rather to explore the properties of the AMC-19 as a tool for use between health professionals and families. Nonetheless, the most common disabilities typically seen in CTCs have been captured, which demonstrates the AMC-19 is applicable and appropriate in several settings and populations.
A possible limitation of the AMC-19 Pilot study was a low initial participation rate. This study was not intended to be a rigorous experimental design requiring a large or predetermined sample size, so convenience and respect for the families' time were the priorities when we selected the sampling strategy. Rather, in this paper, we make a case that complexity is a fundamentally different notion than diagnostic category. Further studies are required to assess the adaptability and utility of the AMC-19 measure in other settings and populations by using a larger sample size.

\section{Future research directions}

Our next step is to assess the validity and clinical utility of the AMC-19 through a larger study by piloting its administration at a CTC. Further research is needed in a population with representation of children with varied diagnoses, chronic impairments or special health care needs. A larger study will evaluate the relationship between parent health and child's complexity for adequate exploration of a wide variety of children with different conditions and ages, as well as a host of other dependent variables like parental stress as a correlate of the AMC-19 scores. These relationships have implications for understanding family demographics, parents' well-being, and organizing service allocation.

Currently, we propose using the AMC-19 primarily as a descriptive account of individual children's complexity. If the AMC-19 is to be used as a comparative instrument, or as a screening or assessment tool, a larger study will inform creating cut-off scores to establish meaningful 'levels' of complexity. What is also not yet known is how much real change in AMC-19 scores might be observed over time as children's development, and their issues, change. Because our samples did not consist of a minimal number of children within specified demographic or other factors, we were unable to determine the amount of invariance in the AMC-19. A more sophisticated research design is required to assess non-invariance in the AMC-19 to provide an adequate conclusion. The implementation of the AMC-19 at a CTC will assess the measure's utility for identifying priority areas for therapy within a clinical setting. Discussions will make it possible to assess how families and service providers will be involved to inform changes as well as future use of the AMC-19 measure in practice.

\section{Conclusion}

Complexity refers to the aggregation of concerns about children's health, and the impact of those concerns. The AMC-19 is an instrument designed to identify the complexity in a child's life to due biological, psychological, social, and environmental issues. The measure is short, easy-to-use, acceptable to families, and has good 
psychometric properties to explore areas of functional concerns and the impact of different areas on the child from the parental perspective. We believe that AMC provides a structured opportunity for parents to report their perceptions and concerns about their child, and as such offers a view that may be complementary to the way that other observers (e.g., clinicians) assess and evaluate a child's situation. This family-centred instrument can be used for initiating dialogue between therapists and families, systematically setting goals, and evaluating the impact of supports of children and families in need of additional services.

\author{
Abbreviations \\ AMC: About My Child; ASD: Autism Spectrum Disorder; CHIEF: Craig Hospital \\ Inventory of Environmental Factors; CP: Cerebral Palsy; CTCs: Children's \\ Treatment Centres; DCD: Developmental Coordination Disorder; \\ ICF: International Classification of Functioning, Disability and Health; \\ IQR: Interquartile Range; PDD: Pervasive Developmental Disorder; \\ SAS: Supports and Services questionnaire; SUO: Service Utilization and \\ Outcomes study
}

\section{Acknowledgements}

The study team is extremely grateful to the families who participated in the studies as well as all the staff from the children's treatment centres. We are thankful to Dr. Olaf Kraus de Camargo for his involvement in development of the AMC with the ICF coding. At the time the study was conducted, CanChild was partially supported by the Research Branch of the Ministry of Health and Long Term Care. We are thankful to Dr. Jan Willem Gorter for his work and support. Dr. Gorter holds the Scotiabank Chair in Child Health Research.

\section{Funding}

This research was funded partly by the Research Branch of the Ministry of Health and Long Term Care. The Research Branch of the Ministry of Health and Long Term Care did not have a role in the design of this study or collection, analysis, or interpretation of the data.

\section{Availability of data and materials}

The datasets used and analysed during the current study are available from the corresponding author on reasonable request.

\section{Authors' contributions}

All authors (UW, PR, JWG, DM, RG) made a substantial contribution in writing, editing, and reviewing all parts of the manuscript. All authors (UW, PR, JWG, $D M, R G$ ) give final approval of this version to be published and take public responsibility for the content of this manuscript as well are accountable for the accuracy of the work. JWG and PR are responsible for the conception and design of the Pilot Study, and UW and JWG are responsible for the conception and design of the Service Utilization and Outcomes study. UW and DM are responsible for the quantitative analysis and interpretation. UW and $R G$ are responsible for the qualitative analysis, and all authors (UW, PR, JWG, DM, RG) are responsible for the qualitative interpretation.

\section{Ethics approval and consent to participate}

All participants in this manuscript provided written informed consent. Ethics approval was received from McMaster University for the Pilot Study (REB \# 6-446) and Hamilton Integrated Research Ethics Board for the Service Utilization and Outcomes study (HIREB \#14-171).

\section{Competing interests}

The authors declare that they have no competing interests.
Received: 28 December 2016 Accepted: 8 May 2018

Published online: 25 May 2018

\section{References}

1. World Health Organization/World Bank Group. World Report on Disability. http://apps.who.int/iris/bitstream/10665/70670/1/WHO_NMH_VIP_11.01_ eng.pdf. Published 2011. Accessed 12 Aug 2017.

2. Newacheck PW, Kim SE. A national profile of health care utilization and expenditures for children with special health care needs. Arch Pediat Adol Med. 2005;159:10-7.

3. Law M, Jaffer S. Measuring the Complexity of Childhood Disability, CanChild Centre for Childhood Disability Research. Hamilton: McMaster University; 2007.

4. Nardi R, Scanelli G, Corrao S, lori I, Mathieu G, Amatrian R. Co-morbidity does not reflect complexity in internal medicine patients. Eur J Intern Med. 2007:18:359-68.

5. Safford MM, Allison JJ, Kiefe Cl. Patient complexity: more than comorbidity, the vector model of complexity. J Gen Intern Med. 2007;22(suppl. 3):382-90.

6. Rosenbaum P, Mesterman R, Law M, Jaffer S, Russell D, Gorter JW, McCauley D, Kertoy M. About My Child, CanChild Centre for Childhood Disability Research. Hamilton: McMaster University; 2008.

7. World Health Organization. International classification of functioning, disability and health (ICF). Geneva: World Health Organization; 2001.

8. Ritzema A, Lach L, Rosenbaum P, Nicholas D. About my child: measuring 'complexity' in neurodisability. Evidence of reliability and validity. Child Care Hlth Dev. 2016;42(3):402-9. https://doi.org/10.1111/cch.12326.

9. Williams U. Factors of service utilization and participation outcomes of children with disabilities (doctoral dissertation). Ontario: McMaster University; 2016.

10. Summers JA, Marquis J, Mannan H, Turnbull AP, Fleming K, Poston DJ, Wang M, Kupzyk K. Relationship of perceived adequacy of services, familyprofessional partnerships, and family quality of life in early childhood service programmes. Int J Disab Dev Educ. 2007;54(3):319-38. https://doi.org/10. 1080/10349120701488848.

11. Kertoy MK, Russell DJ, Rosenbaum P, Jaffer S, Law M, McCauley D, Gorter JW. Development of an outcome measurement system for service planning for children and youth with special needs. Child Care HIth Dev. 2012;39(5):750-9.

12. Walter SD, Eliasziw M, Donner A. Sample size and optimal designs for reliability studies. Stat Med. 1998;17(1):101-10.

13. McCauley D, Gorter JW, Russell DJ, Rosenbaum P, Law M, Kertoy M. Assessment of environmental factors in disabled children 2-12 years: development and reliability of the Craig Hospital inventory of environmental factors (CHIEF) for children-parent version. Child Care HIth Dev. 2013;39(3):337-44.

14. Brown TC, Peterson GL, Brink GE. An enquiry into the method of paired comparison: reliability, scaling, and Thurstone's law of comparative judgment. Colorado: Fort Collins; 2008.

15. Dolnicar S, Bettina G. How constrained a response: a comparison of binary, ordinal and metric answer formats. J Retail Consum Serv. 2007;14(2):108-22.

16. Glaser BG, Strauss AL. The discovery of grounded theory: strategies for qualitative research. Chicago: Aldine; 1967.

17. Pleas S, Pinkerton P. Chronic childhood disorder: promoting patterns of adjustment. London: Kimpton; 1975.

18. Kanuk L, Berenson C. Mail surveys and response rates: a literature review. J Mark Res. 1975;12:440-53.

19. Kuhlthau K, Hill K, Fluet C, Meara E, Yucel RM. Correlates of therapy use and expenditures in children in the United States. Dev Neurorehabil. 2008;11(2): 115-23. https://doi.org/10.1080/17518420701605627.

20. Majnemer A, Mazer B, Lecker E, Leduc Carter A, Limperopoulos C, Shevell M, Rohlicek C, Rosenblatt B, Tchervenkov C. Patterns of use of educational and rehabilitation services at school age for children with congenitally malformed hearts. Cardiol Young. 2008;18(3):288-96. https://doi.org/10. 1017/S1047951108002114.

21. Majnemer A, Shikako-Thomas K, Lach L, Shevell M, Law M, Schmitz N, Poulin C. Rehabilitation service utilization in children and youth with cerebral palsy. Child Care Health Dev. 2013;40(2):275-82. https://doi.org/10.1111/cch.12026.

22. Palisano RJ, Begnoche DM, Chiarello LA, Bartlett J, McCoy SW, Chang H. Amount and focus of physical therapy and occupational therapy for young children with cerebral palsy. Phys Occup Ther Pediatr. 2012;32(4):368-82. https://doi.org/10.3109/01942638.2012.715620.

\section{Publisher's Note}

Springer Nature remains neutral with regard to jurisdictional claims in published maps and institutional affiliations. 